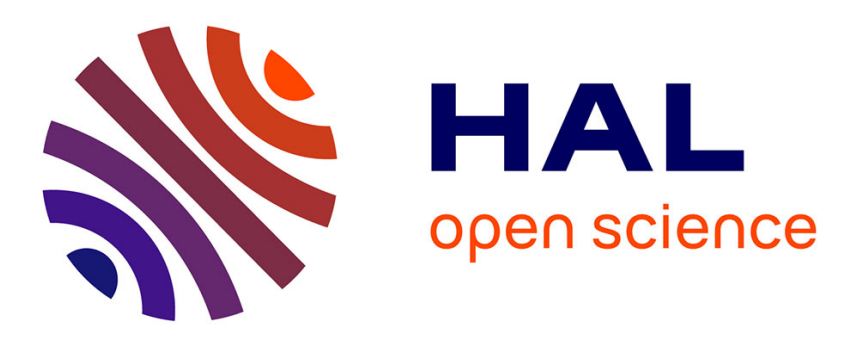

\title{
An elastoplastic and viscoplastic model for porous geomaterials
}

Mountaka Souley, Noémie Lafrance, Christophe Auvray, V. Labiouse, Tikou Belem

\section{- To cite this version:}

Mountaka Souley, Noémie Lafrance, Christophe Auvray, V. Labiouse, Tikou Belem. An elastoplastic and viscoplastic model for porous geomaterials. International Symposium of ISRM "Rock Mechanics and Rock Engineering: From the Past to the Future" (EUROCK 2016), Aug 2016, Cappadocia, Turkey. pp.481-486. ineris-01854304

\section{HAL Id: ineris-01854304}

https://hal-ineris.archives-ouvertes.fr/ineris-01854304

Submitted on 4 Sep 2018

HAL is a multi-disciplinary open access archive for the deposit and dissemination of scientific research documents, whether they are published or not. The documents may come from teaching and research institutions in France or abroad, or from public or private research centers.
L'archive ouverte pluridisciplinaire HAL, est destinée au dépôt et à la diffusion de documents scientifiques de niveau recherche, publiés ou non, émanant des établissements d'enseignement et de recherche français ou étrangers, des laboratoires publics ou privés. 


\title{
An elastoplastic and viscoplastic model for porous geomaterials
}

\author{
M. Souley \& N. Lafrance \\ INERIS, c/o Ecole des Mines de Nancy, Campus ARTEM, Nancy, France \\ C. Auvray \\ Université de Lorraine, CNRS, CREGU, GeoRessources Laboratory, France \\ V. Labiouse \\ Haute Ecole d'Ingénierie et d'Architecture de Fribourg, Fribourg, Switzerland \\ T. Belem \\ Université du Québec en Abitibi-Témiscamingue, RIME, Rouyn-Noranda, QC, Canada
}

\begin{abstract}
Chalk rocks have been used for centuries as strong building materials and for the production of lime. The shallow underground room-and-pillar quarries where chalk rocks were extracted are now abandoned and are enduring the effects of time and weathering which increases their risk of collapse. A large campaign of laboratory tests under different Relative Humidity values (from 90 to $98 \%$ ) was undertaken to describe the short and long term behavior of two chalks. These laboratory tests clearly show an elastoplastic behavior with strain-hardening/softening, a relative humidity-dependent strength, a pore collapse and matrix densification even if the stress level is much higher than that prevailing in situ as well as a time-dependent shear and volumetric strains. A multi-mechanism (tensile, shear, pore collapse/compaction, creep) model of the mechanical behavior for highly porous geomaterials is proposed based on the laboratory characterization and constitutive models published in the literature. The proposed model was implemented in $\mathrm{FLAC}^{3 \mathrm{D}}$ and used to simulate laboratory tests in order to verify and validate the implementation.
\end{abstract}

\section{INTRODUCTION}

Characterization and modeling of the mechanical behavior of compressible materials are well-known issues, and have been studied for a long time: (a) in soil mechanics, including the foundations on soft ground or stability of embankments, structures on compressible soils etc.; (b) in the field of metallurgy for the behavior of metal foam containing voids (one of the first ductile damage model has been proposed by Gurson (1977), and widely used in the literature for geomaterials) or for compaction of metal and pharmaceutical powders, snow or crushed salt compaction (for instance) or in the ceramic industry. The common thread for these materials is that when they are subjected to loadings, significant modifications of their microstructure (compaction, stiffening, increase of their cohesion, etc.) are experimentally observed.

Chalk rocks have been used for centuries as strong building materials and for the production of lime. The shallow underground room-and-pillar quarries where chalk rocks were extracted are now abandoned and are enduring the effects of time and weathering, which in turn increases their risk of collapse. The risk of instability, involving natural or anthropogenic underground structures, is an issue for more than 10000 towns in France. In order to investigate the causes of underground quarry collapse and to aid preventive strategies, we carried out a study of the physico-mechanical behaviour as well as the water-rock interaction of chalks sampled from abandoned pillars in two underground quarries, in situ-instrumented and monitored by INERIS (Institut National de l'Environnement Industriel et des Risques), in the Parisian Basin, France. There are two partially flooded underground chalk quarries, subjected to water table fluctuations, at Estreux (EX) and St-Martin-Le-Nœud (SM) in northern France (Gombert et al. 2013), located at an average depth of 20 to $25 \mathrm{~m}$.

A large laboratory characterization was conducted to understand the short and long terms behavior of these two chalks depending on the relative humidity, although in the context of this paper we will limit ourselves to the relative humidity levels ranging between $90 \%$ and $100 \%$ which are the most representative of the in situ conditions of abandoned quarries. The ageing aspects of these chalks as well as the impact of weathering on the macro-mechanical properties are described in Lafrance et al. (2016).

Indeed, several models of mechanical behavior for highly porous materials (chalk for the oil industry, metal powders or PVC in metallurgy or 
pharmaceutical industry, ceramics, etc.) can be found in the literature (Homand \& Shao 2000, Azami \& Khoei 2006, Wu et al. 2005). However, many of these models are limited to the short-term response. Based on our previous laboratory tests, a new constitutive model (extending previous works) is proposed to account for deformations and the role of relative humidity in the short-term and long-term behavior. Typically, the time-dependent behavior is governed by deformation processes corresponding to different physical mechanisms for changing material microstructure.

\section{BRIEF REVIEW OF MODELS FOR HIGHLY POROUS GEOMATERIALS}

The mechanical behavior of very porous rocks is widely varied and depends on the mean stress and the loading path. At low stress levels, porous rocks break by the development of one or more shear bands accompanied by a softening behavior: strains at the microscopic scale consist of microcracks dilatancy and grains rotation. Under high mean stresses, porous rocks undergo a hardening behavior which is microscopically associated with volumetric strains due to compaction. Inelastic compaction of the pore space occurs on the debris and/or sliding through the contacts between grains whereas brittle failure dominates the microscopic processes. As a function of loading path, the material may eventually break by localization of shear strain.

A pioneering extension of the theory of plasticity for metals to the plastic behavior of soils was conducted by Drucker and Prager (1952): they extended the failure criterion of von Mises to take into account the confining pressure in granular media. One of the first criterion including closed yield surfaces (commonly called "cap" surfaces) with their numerical implementation without smoothing the edges was presented by DiMaggio and Sandler (1971). Even if such "cap" models were originally developed for sands, they were used successfully for other materials such as clay and concrete.

For the modeling of porous geomaterials, significant advances have been made in recent decades. Several plastic models have been proposed to account for the influences of porosity, expansion and collapse of pores (Seifert and Schmidt 2009). Other studies have investigated the propagation of microcracks, the strain localization and viscous deformation in porous materials (Mroginski et al. 2011). Based on the working reference of Gurson (1977), a number of advances have been made on the micromechanic analysis for the purpose of determining the macroscopic plastic yield function and plastic potential through a homogenization scheme (Magous et al. 2009). All these models have clearly shown that the macroscopic behavior of porous materials depends on the porosity and its evolution.
Most short term models of porous geomaterials behavior are based on a "cap" yield surface whose shape can be spherical, elliptical or composite and taken into account other mechanisms: shearing, pore collapse and/or tensile. In the case of chalks, one can refer to the constitutive and numerical developments achieved in the framework of the European program PASACHALK "Mechanical Behaviour of Partially Saturated chalks and Multiphase Fluid-skeleton" (CONTRACT NO: ENK6-2000 -00,089). However, these models do not generally take into account the effect of relative humidity and creep which are predominant phenomena regarding the long-term stability of abandoned quarries.

\section{PHENOMENA CONSIDERED FOR THE TWO CHALKS}

A large campaign of laboratory tests was undertaken to characterize the short and long terms behavior of these two chalks. It includes several uniaxial and triaxial compression tests performed on dry and saturated samples as well as for different relative humidity values ranging from 90 to $98 \%$ typically encountered in situ, hydrostatic tests aimed at characterizing the volumetric yield surface and uniaxial creep tests with numerous stress levels and relative humidity values. Figure 1 illustrates the typical short and long terms behavior for a given relative humidity and given chalk, the impact of a specific relative humidity stage and of the sample flooding during the last stress and relative humidity levels.

These laboratory tests clearly indicate an elastoplastic behavior with strain-hardening/softening, the relative humidity-dependent strength, the pore collapse of chalk even if the last stress level tested is much higher than that prevailing in situ, as well as time-dependent shear and volumetric strains. More precisely, for the short term behavior: (a) a linear behavior and an appearance of plastic strains at low deviatoric stress (the elastic limit is low); (b) under low confining pressures, the samples failure corresponds to the formation of a shear band inclined with respect to the sample axis. There is a dependence of the mechanical behavior on the relative humidity; (c) a post-peak behavior has been captured with the external displacement transducer. The hydrostatic compression carried out on the two chalks clearly indicates a similar behavior than other geomaterials (sandstone and limestone: Wong \& Baud 2012) under hydrostatic compression path; that is to say, two to three distinct domains of behavior i.e. elasticity, pore collapse and densification.

For the long-term behavior (a) simultaneous measurements of axial and lateral strains during creep tests show that volumetric strains are not negligible according to the relative humidity and stress levels; (b) the creep strain rate increases in a non-linear manner with applied deviatoric stresses and relative humidity. 


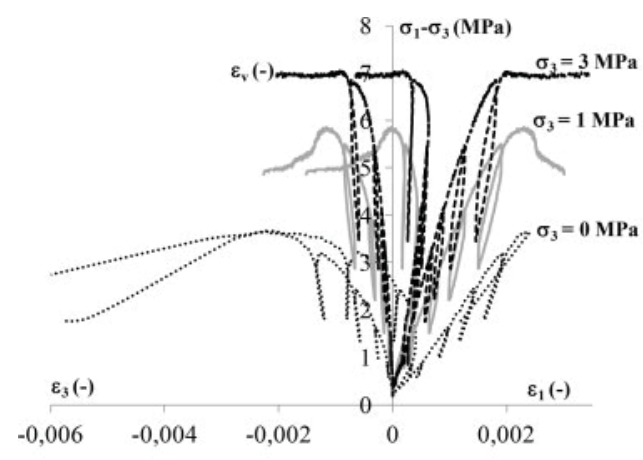

(a)

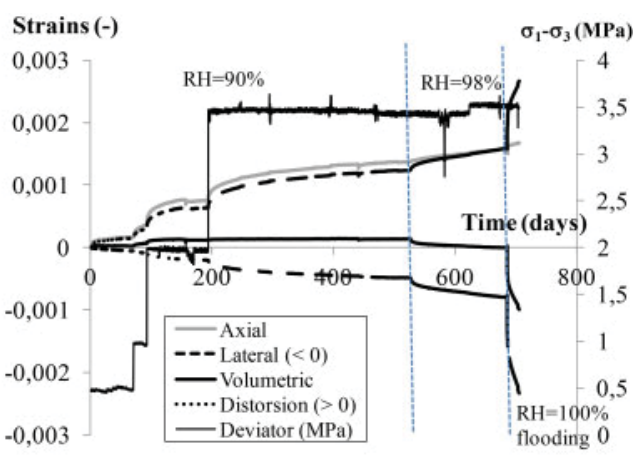

(b)

Figure 1. Typical behavior of the studied EX chalks: (a) triaxial compression test (deviatoric stress vs strains) at $98 \%$ of RH, (b) uniaxial creep test showing the effects of stress and hygrometry ( $90 \%$ and $98 \% \mathrm{RH})$ and flooding.

\section{PROPOSED CONSTITUTIVE MODEL}

Although laboratory tests have shown that the short and long terms behavior is strongly influenced by the relative humidity, in this paper we restricted the rheological development to isothermal conditions and a given fixed relative humidity. A more general model will be addressed in the near future.

The rheological model proposed is based on results obtained from different laboratory characterizations. We recall the main features of the short-term mechanical behavior observed on the chalk samples under triaxial tests. They can be summarized as follow: the behavior is linear under low deviatoric stresses; the loss of linearity of lateral and axial strain-stress curves begins at a very low value of deviatoric stress. Depending on the considered chalk, the volumetric behavior according to the triaxial loading path is contracting and/or dilatant.

Figure 2 summarizes the proposed modeling of each mechanism of the short-term response (ST) which is characterized by (a) an elastic yield, a peak strength and a residual strength based on the Drucker-Prager's criterion. The advantage of this criterion compared to Mohr-Coulomb or Hoek-Brown ones is the dependency on the intermediate principal stress $\sigma_{2}$; (b) a strain hardening based on the test data and strain softening which is assumed to be symmetrical and homothetic to the hardening due to the lack of experimental results. The strain hardening and softening are modelled by an exponential function with respect to the internal plastic variable (plastic distortion).

For the pore collapse mechanism (volumetric cap yield), the yield function is based on the Tvergaard (1990) criterion, that is to say, an incorporated elliptical yield surface for both pore collapse and compaction. The main advantage of this micromechanicsbased criterion is that the yield function depends explicitly on the porosity of the medium. The hardening due to pore collapse is governed by a local hardening variable which depends on the macroscopic plastic deformation with respect to the pore collapse mechanism (e.g. volumetric plastic strain due to the hydrostatic failure) and determined by the principle of equivalence plastic energy.

Finally, for the short-term response, failure is based on a combination of a cut-off in tensile, a yield function based on Drucker-Prager's criterion in shear (including hardening and softening) and an elliptical yield surface for both pore collapse and compaction.

The mathematical expressions of each of the mechanisms considered in the short term are summarized in Table 1. In this table, the subscript 0 expresses the mechanism initiation (shear or pore collapse), the subscript $\mathrm{m}$ is related to parameters at failure, $q$ and $p$ are respectively the deviatoric stress and the mean stress, $\phi$ corresponds the total porosity.

The time dependent behavior is governed by deformation processes corresponding to different physical mechanisms for change in material microstructure. Using the formalism proposed by Perzyna (1966), it is possible to express the total viscoplastic strain rate.

More precisely, based on the main observations from creep tests, a creep model is proposed by introducing a creep threshold function depending on the relative humidity in the well-known Lemaitre's law. By taking into account all the observed phenomena (detailed in the beginning of this section), the following expression was proposed for the viscoplastic strain rate tensor:

$\underline{\dot{\varepsilon}}^{\mathrm{vp}}=\mathrm{A}\left(\frac{\mathrm{q}-\mathrm{q}_{0}}{\sigma_{0}}\right)^{\mathrm{n}} \varepsilon_{\mathrm{eq}}{ }^{\mathrm{m}} \frac{\partial \mathrm{q}}{\partial \underline{\sigma}}$

where $\mathrm{A}$ is the material viscosity depending on the relative humidity, $\sigma_{0}$ the reference stress, $n$ a dimensionless exponent corresponding to the deviatoric stress power factor, $m$ the exponent of hardening work, $\varepsilon_{\text {eq }}$ the viscoplastic strain (or viscoplastic distortion), $\mathrm{q}_{0}$ the deviatoric stress threshold, $\mathrm{q}$ the current deviatoric stress, $\sigma$ the stress tensor.

Although creep tests showed the occurrence of deferred volumetric strains, in this first approach they will be neglected. 


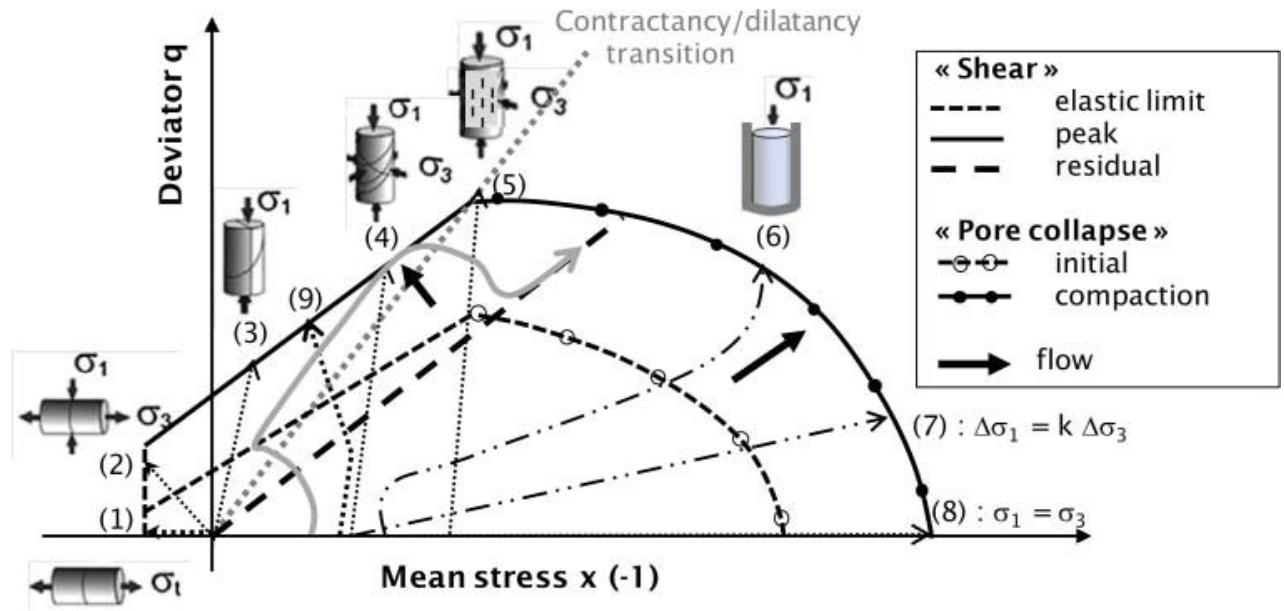
(1) : uniaxial tensile failure
(2) : triaxial tensile failure
(3) : brittle failure (lowconfining pressure)
(4) : triaxial compression failure (softening)
(5) : triaxial compression failure (ductile)
(6) : failure under oedometric conditions
(7) : path of proportionnel test
(8) : path of hydrostatic compression
(9) : path of lateral extension

7 Example of stress path in shear

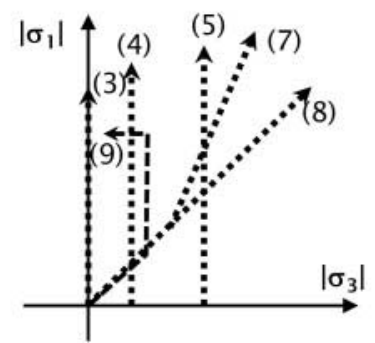

Figure 2. Schematic representation of initial yield surfaces in tension, shear and pore collapse as well as the hardening and main stress pathway for conventional tests.

Table 1. Summary of yield function and plastic potential flow variables used in the proposed model for shear and pore collapse mechanisms.

\begin{tabular}{|c|c|c|}
\hline Mechanism & Mathematical expression & Material parameters \\
\hline Tensile failure (no flow) & Cut-off and associated flow rule & $\sigma_{\mathrm{t}}$ \\
\hline Shear mechanism: yield function & $\mathrm{F}_{\mathrm{s}}(\underline{\sigma})=\mathrm{F}_{\mathrm{s}}\left(\sigma_{\mathrm{ij}}\right)=\mathrm{q}+\alpha\left(\mathrm{p}-\mathrm{p}_{0}\right)=0$ & $\mathrm{p}_{0}$ \\
\hline $\begin{array}{l}\text { Shear mechanism in pre-peak: flow func- } \\
\text { tion depending on the internal variable } \\
(\gamma: \text { plastic distortion })\end{array}$ & $\alpha=\alpha(\gamma)=\alpha_{\mathrm{m}}-\left(\alpha_{\mathrm{m}}-\alpha_{0}\right) \mathrm{e}^{-\mathrm{b}_{1} \gamma}$ & $\alpha_{0}, \alpha_{\mathrm{m}}, \mathrm{b}_{1}$ \\
\hline Shear mechanism: plastic potential & $\mathrm{G}_{\mathrm{s}}(\underline{\sigma})=\mathrm{G}_{\mathrm{s}}\left(\sigma_{\mathrm{ij}}\right)=\mathrm{q}+\beta \mathrm{p}$ & \\
\hline $\begin{array}{l}\text { Shear mechanism: contractancy / dilatancy } \\
\text { transition }\end{array}$ & $\beta=\beta(\gamma)=\beta_{\mathrm{m}}-\left(\beta_{\mathrm{m}}-\beta_{0}\right) \mathrm{e}^{-\mathrm{b}_{1} \gamma}$ & $\beta_{0}, \beta_{\mathrm{m}}$ \\
\hline Shear mechanism in post-peak & Symmetrical and homothetic to $\alpha$ & $\mathrm{f}$ (homothetic factor) \\
\hline Pore collapse mechanism: yield function & $\mathrm{F}_{\mathrm{c}}(\underline{\sigma})=\mathrm{F}_{\mathrm{c}}\left(\sigma_{\mathrm{i}}\right)=\frac{\mathrm{q}^{2}}{\sigma_{\mathrm{M}}^{2}}+2 \mathrm{q}_{1} \phi \cosh \left(\mathrm{q}_{2} \frac{3 \mathrm{p}}{2 \sigma_{\mathrm{M}}}\right)-\left(1+\left(\mathrm{q}_{1} \phi\right)^{2}\right)$ & $\mathrm{q}_{1}, \mathrm{q}_{2}, \phi_{0}$ \\
\hline Pore collapse mechanism: potential & Associated flow rule & \\
\hline Pore collapse mechanism: hardening & $\sigma_{\mathrm{M}}=\sigma_{\mathrm{M}}(\xi)=\sigma_{\mathrm{M}}^{0}(1+\mathrm{a} \xi)$ & a \\
\hline
\end{tabular}

All parameters have been identified from triaxial and hydrostatic compression tests for the short-term response, and from creep tests at different deviatoric stress levels for the long-term behavior.

More precisely, by having at least three triaxial tests at different confining pressures, one hydrostatic compression test and one creep test, the rheological parameters can be identified of the proposed model for a given fixed relative humidity. Although the pore collapse mechanism is not predominant in the case of studied chalks in relation to the low in situ stress state (depth of 20-30 m), we kept this mechanism in 


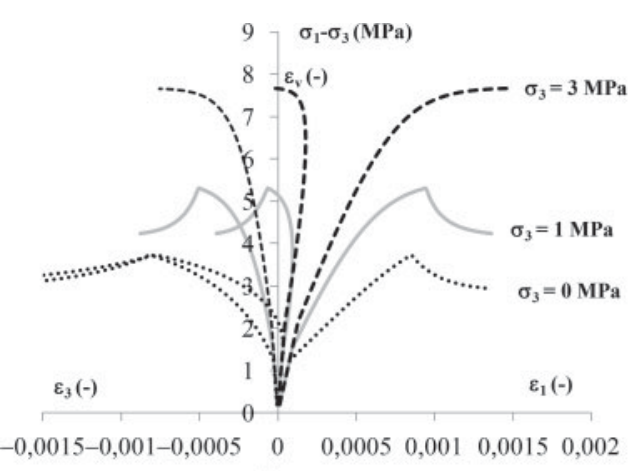

(a)

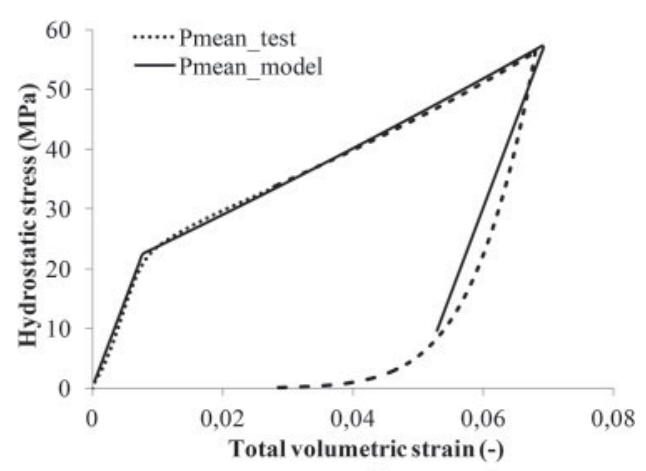

(b)

Figure 3. (a) Triaxial compression test simulations using the proposed model: deviatoric stress vs strains; (b) hydrostatic test and corresponding simulation showing the pore collapse hardening (pore collapse stress $\sigma_{\mathrm{M} 0}=21 \mathrm{MPa}$ ).

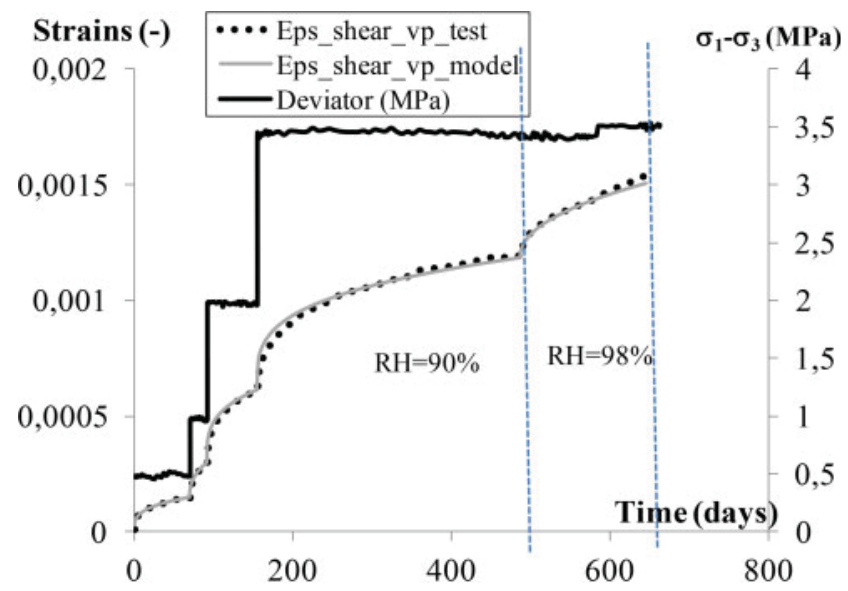

Figure 4. Viscoplastic shear strain for a multi-stage uniaxial creep test and simulation ( 1 st stage $\sigma_{1}=0.5 \mathrm{MPa}$ and RH $=90 \%$; 2nd stage $\sigma_{1}=1 \mathrm{MPa}$ and $\mathrm{RH}=90 \%$; 3rd stage $\sigma_{1}=2 \mathrm{MPa}$ and $\mathrm{RH}=90 \%$; 4th $\sigma_{1}=3,5 \mathrm{MPa}$ and $\mathrm{RH}=90 \% \& \mathrm{RH}=98 \%$ ).

the model with the aim of its use to other deeped chalks (petroleum applications) or other porous and compressible materials.

\section{NUMERICAL IMPLEMENTATION AND VERIFICATION}

The proposed multi-mechanism model was implemented by coupling the viscoplastic and short-term response in the three-dimensional explicit finitedifference code, FLAC $^{3 \mathrm{D}}$. At each step, the computation of new stresses is achieved by testing firstly the current deviatoric stress with respect to the threshold and then calculating the appropriate viscoplastic strain increment. The strain increment for instantaneous response are computed, leading to correct the stress when failure in tensile or in shear and/or pore collapse is detected.

In order to verify the model (constitutive equations and numerical implementation), several triaxial compression tests with confining pressures of 0,1 , and
$3 \mathrm{MPa}$ are simulated. Figure $3 \mathrm{a}$ presents the deviatoric stress - axial, lateral and volumetric strain curves for different confining pressures.

The resulting curves display four regions (elastic, hardening in pre-peak, softening in post-peak and residual phases). These curves are qualitatively similar to the experimental ones (which were not reported herein). In addition, the elastic limit, the peak and residual strengths derived from these simulations are compared with the theoretical envelopes with a good agreement. Similarly, simulation of multistage (deviatoric stress and relative humidity) creep test, not shown here, indicates a good agreement with the experimental curves.

On the Figure $3 \mathrm{~b}$ we present the evolution of hardening during a hydrostatic compression test carried out on one of the two chalks. For this test, the mean stress at the beginning of pore collapse is about $21 \mathrm{MPa}$. As a result, a linear fitting as a function of the volumetric plastic deformation can reproduce this hardening. Finally, it may be noted that even for a hydrostatic pressure of $60 \mathrm{MPa}$, there is no densification of the chalk (stiffening of modules). 
The model is now applied to simulate some creep tests performed under uniaxial compression condition. The evolutions of axial stress with time for the four tests are given in Figure 1b. The numerical simulation carried out with the model is shown in Figure 4. Qualitatively and quantitatively, the model response is in good agreement with the experimental curves.

\section{CONCLUSION}

This paper presents the development of a multimechanism constitutive model for porous geomaterials, its numerical implementation in the threedimensional code $F L A C^{3 D}$, as well as its verification. Firstly, a non-linear elastoplastic model based on the interpretation of laboratory test performed using a cutoff in tension, the Drucker-Prager's failure criterion for shear, an elliptical yield surface for both pore collapse and compaction based on Tvergaard (1990)'s criterion, is presented.

Simulation of triaxial compression tests at different levels of confining pressure provides a verification of the implemented model. The resulting curves display four regions (elastic, hardening in pre-peak, softening in post-peak and residual phase) in accordance with the laboratory tests.

The next step is to incorporate the changes in viscosity as a function of relative humidity and the deferred volumetric strains observed on samples in the proposed model and finally to perform some long-term stability applications at pillar and quarry scales.

\section{REFERENCES}

Azami, A.R. \& Khoei, A.R. 2006. 3D computational modeling of powder compaction processes using a threeinvariant hardening cap plasticity model. Finite Elements in Analysis and Design 42: 792-807.
DiMaggio, F. L. \& Sandler, I. S. 1971. Material model for granular soils, J. Eng. Mech. Div. Am. Soc. Civ. Eng., 97: 935-950.

Gombert P., Auvray C. \& Al Heib M. 2013. In-situ and laboratory tests to evaluate the impact of water table fluctuations on stability of underground chalk mines. Procedia Earth and Planetary Science 7: 304-308.

Gurson, A.L. 1977. Continuum theory of ductile rupture by void nucleation and growth: Part I - Yield criteria and flow rules for porous ductile media. J. Engng Materials and Tech. 99: 2-15.

Homand, S. \& Shao, J.F. 2000. Mechanical Behaviour of a Porous Chalk and Water/Chalk Interaction, Part II: Numerical modelling. Oil \& Gas Science and Technology, 55(6): 599-609.

Lafrance, N., Auvray, C., Souley, M. \& Labiouse, V. 2016. Impact of weathering on the macro-mechanical properties of chalks. Engineering Geology (to appear).

Magous, S., Dormieux, L. \& Barthélémy, J.F. 2009. Micromechanical approach to the strength properties of frictional geomaterials. Eur. J. Mech. A/Solids 28: 179-188.

Mroginski, J.L., Etse, G. \& Vrech, S.M. 2011. A thermodynamical gradient theory for deformation and strain localization of porous media. Int. J. Plast. 27: 620-634.

Perzyna, P. 1966. Fundamental problems in viscoplasticity. Adv. Appl. Mech. 9: 243-377.

Seifert, T. \& Schmidt, I. 2009. Plastic yielding in cyclically loaded porous materials. Int. J. Plast. 25: 2435-2453.

Tvergaard V. \& Viggo 1990. Material failure by void growth to coalescence. Adv. Appl. Mech, 27: 83-151.

Wong, T.-F. \& Baud, P. 2012. The brittle-ductile transition in porous rock: A review. J. of Structural Geology 44: 25-53.

Wu, C.Y., Ruddy, O.M., Bentham, A.C., Hancock, B.C., Best, S.M. \& Elliott, J.A. 2005. Modelling the mechanical behaviour of pharmaceutical powders during compaction. Powder Technology 152(1-3): 107-117. 